BIORHEOLOGY, 21 ; I-III, 1984

$0006-355 X / 84 \$ 3.00+.00$ Printed in the USA.

Copyright (c) 1984 Pergamon Press Ltd. A11 rights reserved.

\title{
EDITORIAL:
}

SOFTWARE SURVEY SECTION

The introduction of the new Software Survey Section to BIORHEOLOGY is to encourage the open exchange of information on software programs unique to our professional field. With the rapid penetration of computers into academic and industrial institutions has come a parallel increase in the number of scientists and researchers designing their own software. The existence of much of this software remains unknown to even those of us who could most benefit from its use. We believe that it is of vital importance to our readers that such information be made available. We believe also that a professional journal is the best place to share such information. Your contribution would be most welcome.

The questionnaire on the following pages is designed to assist you in reporting on software that you may have developed or be in the process of developing. By completing this form, your information will reach thousands of your colleagues who may benefit from your work and may possibly offer suggestions for further enhancements to your software. Please complete the enclosed form and return it to:

$$
\begin{gathered}
\text { Dr. A. L. Copley } \\
\text { Biorheology } \\
\text { Polytechnic Institute of New York } \\
333 \text { Jay Street } \\
\text { Brook1yn, NY } 11201 \text {, U.S.A. }
\end{gathered}
$$

We do not intend to review or comment on the contents of the questionnaire. It will be published as is in order to expedite the information cycle process. I would welcome any comments you may have. 
NAME OF JOURNAL

Title of software package:

It Is: [ ]Application program [ ]Utility [ ]0ther
Specific area
(e.g. Thermodynamics, Inventory Control)
Software developed for [name of computer(s)]
in [language(s)]
to run under [operating system]
and is available in the following media:
[ ] Floppy disk/diskette. Specify:
[ Size Density Magnetic tape. Specify:
$\quad$ Size Density

Distributed by:

Minimum hardware configuration required:

Required memory:

User training required: $[$ ]Yes $[$ ]No

Documentation: [ ]None [ ] Minimal [ ]Self-documenting

[ ]Extensive external documentation

Source code available: $[$ ]Yes $[$ NNo

Leve1 of development: [ ]Design complete [ ]Coding complete

[ ]Fully operational [ ]Collaboration would be welcomed

Is software being used currently? [ ]Yes $[$ No

If yes, how long? ___ If yes, how many sites?

Contributor is available for user inquiries: $[$ YYes $[$ NNo

(continued)

PERGAMON PRESS

Maxwe11 House, Fairview Park, Elmsford NY 10523, USA

Headington Hill Hal1, Oxford OX3 OBW, England

[This Software Description Form may be photocopied without permission] 
Description of what software does [200 words]:

Potential users:

Fields of interest:

Name of

contributor:

Institution:

Address :

Telephone number:

\section{\# \# \# \# \# \# \#}

Reference No. [Assigned by Journal Editor]

[The information below is not for publication.]

Would you like to have your program:

$$
\begin{aligned}
& \text { Reviewed? [ ]Yes }[\text { NNo }[\text { Not at this time } \\
& \text { Marketed and distributed? }[\text { YYes }[\text { Noo }[\text { NNot at this time }
\end{aligned}
$$

[This Software Description Form may be photocopied without permission] 